\section{Attending to the Rhythms of the Sea, Place and Gendered Cultures in Interviewing Fishers and Fishing Families}

\section{Madeleine Gustavsson}

\subsection{Introduction}

Social scientists are increasingly paying attention to the socio-cultural lifeworlds - or contexts—of fishers and fishing (Siriwardane-de Zoysa and Hornidge 2016; Urquhart et al. 2011), yet how we come to know these lifeworlds has been under-explored. The current chapter reflects on the methodological issues of a research project which sought to examine the lives of fishers and fishing families in context. I draw on my own experiences 'in the field' focusing on particular ethical and practical challenges that emerged when interviewing fishers and their families (including women and adult children) in a small-scale fishing community in North Wales, UK.

During the course of the research I spent a total of two months (two weeks at a time) in the study area in 2014-2015. I was using various

\footnotetext{
M. Gustavsson (ه)

European Centre for Environment and Human Health, University of Exeter, Truro, UK
}

Ruralis-Institute for Rural and Regional Research, Trondheim, Norway e-mail: madeleine.gustavsson@ruralis.no 
in-depth qualitative interview techniques, such as repeat interviews (Riley and Harvey 2007), individual interviews, joint interviews (Riley 2014) as well as couple interviews (Valentine 1999) and participant observation. I interviewed male fishers (MF) and members of fishing families-female partners $(\mathrm{FP})$, sons $(\mathrm{S})$ and daughters $(\mathrm{D})$. The age of participants ranged from 18 to 75 . The interview participants predominantly spoke Welsh but were interviewed in English, which presented both challenges and advantages which will be discussed in this chapter. When conducting this research, I noticed there has been relatively little scholarly attention to the use of qualitative methods in fisheries research. The research therefore drew on literature in other social science fields-primarily agriculture (Kuehne 2016; Riley 2010)_and those social researchers taking a more feminist (and socio-cultural) approach (McDowell 1992; Rose 1997; Pini 2005).

The chapter begins with exploring practical and ethical issues around getting access and fitting in with the rhythms of fishing. Then it moves on to discuss emplacement of interviews and the importance of considering associated social dynamics. This is followed by an exploration of some challenges around getting access to the stories of women in fishing families and the different social and spatial contexts which family interviews can constitute. The chapter ends with highlighting some issues around ethical interviewing and a reflection on researcher positionality.

\subsection{Getting Access and Fitting in with the Rhythms of Fishing}

Whilst the UK government publicly registers licensed boats, there is no straightforward way in which to identify fishers. This is especially the case for the small-scale fishing sector which, in the main, falls outside the membership of Producers' Organisations (POs). As such, small-scale fishers and (even more so) their families compose what Heckathorn (2002) calls a 'hidden population'. Identifying and contacting potential participants and securing interviews therefore involved seeking out participants which, in my research, relied on 'chain-referral sampling' (Heckathorn 2002) with local fishing associations as the initial point of contact. 
I faced several challenges when researching fishers and fishing households, with the step of actually pinning down and arranging interviews being the first test. Arranging interviews with people who fish was highly dependent on weather, tides and season:

I have to work the tides, so you can't sort of turn up here and go fishing. You have got to be there on certain times of the tide. If the weather is good I would probably fish seven days a week. (MF-10)

Fishers in the study area were very busy during the summer months as they tried to make the most of the prosperous fishing season and were, inevitably, very hard to interview at this time of the year. Whilst there are various ways to relate to this seasonality, I avoided interviews in the summer. My experience was also that it was difficult to arrange interviews in advance as fishers first needed to know what the weather would be like and whether they would be fishing or not. I negotiated this by approaching potential participants by telephone prior to visiting the area. Whilst in the area, interviews were either provisionally booked at any day of the visit or scheduled one or two days in advance which allowed participants to forecast the weather conditions. Whilst this approach involved a lot of phone calls in an area with poor mobile phone reception, this proved to be an efficient way to arrange interviews with fishers in the inshore fishery who are typically not at sea for longer than a day at a time.

As the time which participants could spare for an interview limited its potential depth, I used 'repeat interviews' (Riley and Harvey 2007) in which I could return to the same participants following the first research encounter. This approach had a threefold advantage. First, it allowed me to use a flexible interview design whereby I (or participants) could cut interviews off and pick them up again next time if the respondents were busy. As highlighted earlier, fitting in around the 'rhythms' of fishing (in particular tides, weather and season) was key to getting access to participants and to enable their rich stories to be told. Second, returning to the same participant allowed for trust and rapport to develop over time (Crang and Cook 1995). Turning up a second time gave participants a sense that I was interested in what they had to say, often leading to richer stories providing me a deeper understanding of their lives. A third 
advantage of returning to the same participant was that it allowed a 'triangulation' of what participants had said in the past-comparing narratives produced in different relational and spatial contexts (Riley 2010).

\subsection{Interview Emplacements and Social Dynamics}

Choices pertaining to interview location, or 'emplacement', have special importance. Research has suggested that places are filled with meaning and can facilitate different memories to be told in an interview (Crang and Cook 1995; Riley 2010). For the context of fishing, Williams (2008, 64) suggests that interviews in fishing homes 'provided reference points for different stories [...] such as photographs of various fishing boats, which were proudly displayed on many of these households' walls'. What these authors have in common is the recognition that the place itself has importance for the knowledge produced in interviews. As Riley (2010) argues, the methodological literature often suggests one should look for a quiet and private place-free from disturbances-but, he argues, by choosing such a location the researcher will miss out on the spontaneous disturbances and everyday activities going on around the interview. Riley $(2010,653)$ highlights that, in his study of family farms, 'being in place and talking about (or through) place allowed the interview to "bring in" other respondents and narratives' than what would have emerged in a standard one-to-one interview. He also argues that this approach places the 'place' (in his case 'the farm') as a 'subject' of the interview.

Informed by these ideas, and to allow for interviews to take place in locations with meaning to participants, I asked participants to choose their preferred location. This approach resulted in a number of interview locations, including fishing coves, inside vans, in people's homes, in their boat sheds, in cafés, on boats (onshore) and in pubs.

Their location choices invariably introduced ethical and practical considerations, with some interview settings proving more suited than others for interviewing fishing families and fishers. Important to this discussion is the distinction between individuals and the community and how 
fishers balance their competitiveness and cooperation through secrecy (Gustavsson et al. 2017; Palmer 1990). The following fieldnotes extract reflect on interviews in public spaces:

I went to the pub to interview a fisher [...] After a little while another fisher walked in. They said hello. He sat down in the bar, ordered a pint. They spoke in Welsh. Laughed. I tried to continue the interview. After a while I realised I couldn't ask most of my questions as they avoided answering questions about their fishing activities in front of another fisher. (Author's fieldnotes)

'Private' and 'public' interview locations therefore present different challenges and opportunities for the interviewer. Public locations, such as a pub, sometimes proved difficult due the presence of other people that could overhear conversations. I quickly learnt that fishing participants were unwilling to share certain types of information in public, and especially with the presence of other, competing, fishers. Fishers were 'secretive' about their fishing activities (Gustavsson et al. 2017) which meant public spaces (e.g. pubs; shared fishing sheds) tended to be inappropriate settings in which to explore these activities in-depth. In contrast, interviews in people's homes as well as other locations (fishing coves, boats and sometimes private sheds) allowed a more productive space for discussions of fishing practices and enabled opportunities to talk about personal issues and business matters — with some fishing secrets generally being more openly shared and discussed within the familial context.

Nevertheless, other researchers have expressed caution around conceptualising the home as an entirely 'private' setting, as the participation and presence of a diverse set of family members in the home can influence what narratives are produced. Aitken $(2001,77)$ notes: 'Lack of privacy during separate interviews can silence participants, but it may also engender coercion if partners are able to listen in on conversations'. Whilst this cautionary note is ethically important when discussing personal and familial issues, my experience was that it was not entirely possible to control the social dynamics of who else was present in an interview situation-neither in those spaces labelled public nor private. In practice, sometimes one-on-one interviews unexpectedly became group interviews 
as other people joined in. I decided to embrace, rather than resist, such unexpected turns, inspired by Kuehne's (2016) approach and recommendations for successful interactions with farmers. Taken together it could be argued that whilst there are advantages and challenges with both public and private interview localities, these are associated with important and specific ethical considerations.

A further aspect to consider when choosing interview locality is Riley and Harvey's (2007) suggestion that 'repeat interviews' with the same participant(s) could be located in different places_enabling different types of 'emplaced' discussion. My experience with using this approach was that repeat interviews similarly helped to expand the number of themes covered, as well as facilitate different spatial and relational contexts. In some cases, participants wanted to show something that had been talked about in the interview, such as a fishing cove, boats and fishing gear, sheds, specific areas of the sea and a maritime museum.

I will show you my garage later, it is full of fishing shit. (MF-22)

I'll show you the boats later on if you want. We can go there by car. (MF-28)

By following participants to these places, the interview became mobile. This approach is akin to Riley's (2010) method of 'emplacing' the interview. In particular Riley (2010) highlights the added value of 'walking interviews'. Although the nature of fishing and the sea mean that walking interviews are more problematic, the approach of allowing fishers to guide the spatial direction of the interview was one borrowed from this literature on mobile methods. This offered the advantage of emplaced discussions in which fishing gear, boats and other fishing places could be discussed and observed.

The fisher wanted to show me where the boats where moored and I decided to follow. It was really good to see for myself how the boats were placed and where the quay pots were located as this wasn't really clear in the interviews. Yet I could not help myself from being frustrated that the recorder was off and that the conversations that followed were unrecorded. (Author's fieldnotes) 
As highlighted in the fieldnotes extract above, the emplaced conversations that followed the interviews were often unrecorded, although a research fieldnote diary was kept noting these observations immediately after returning from 'the field'.

A further way in which to emplace the interview discussion could be to accompany fishers out to sea (e.g. Pálsson 1994; Anbleyth-Evans this volume). Whilst this was not a possibility in my study due to health and safety regulations and cost of enabling courses, researchers could further explore the advantages of locating interviews-and other ethnographic methods - at sea. This could help the researcher to triangulate their findings by also observing the 'doings' at sea-not only the narration of fishing practices and fishing lives.

An important consideration, however, is that the sea is a private and lonely place which could pose significant safety risks to researchers (Sampson and Thomas 2003). Expanding on the theme of risk and safety, Chiswell and Wheeler (2016) highlight risks to the researcher in the context of interviews with farmers (see also Chiswell et al. this volume). They particularly note that farm geographies—such as the social and rural (remote) context of farming - expose young (female) researchers to particular risks. This, they suggest, was particularly the case when researchers were entering someone's home in a remote locality without adequate phone signals. In my research, researcher safety was something that had to be continuously considered. In particular, the risks associated with letting participants choose the place of interview. As the photo (Fig. 3.1) illustrates, interview settings were often in remote localities, unknown to the researcher, with no other people around. This highlights the sometimes-precarious position of researchers in the field and the importance of having a 'lone worker policy' and possibly a 'buddy system'1 in place.

\footnotetext{
${ }^{1}$ Chiswell and Wheeler $(2016,3)$ recommend to always let somebody know the 'details of when, where and who' of the interview and when you are expected to return.
} 


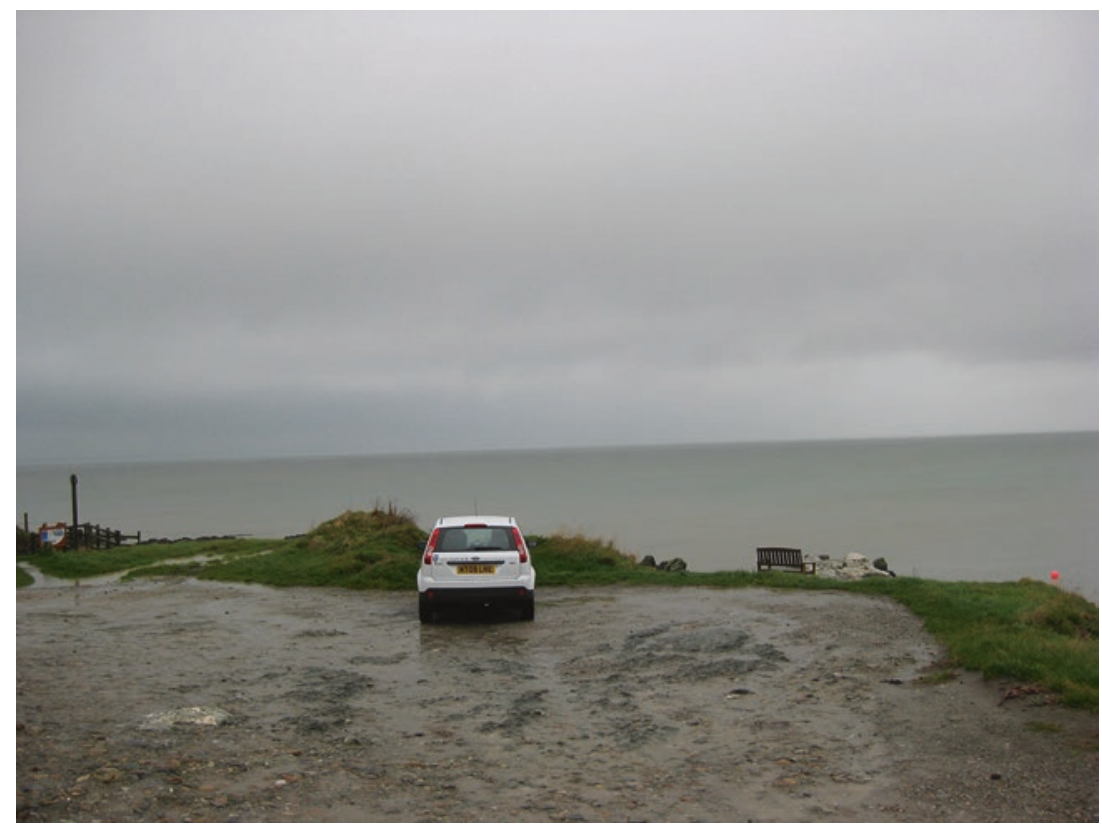

Fig. 3.1 A typical interview location by a fishing cove

\subsection{Getting Access to the Stories of Women}

During the research process I found that establishing contacts with family members, especially people other than the 'male fisher', was especially difficult. Male fishing partners often referred women and adult children to take part in the study and thus could act as gatekeepers (Mandel 2003). This role meant they could also avoid introducing their family members to the researcher:

When finishing the interview I asked the fisher if maybe I could speak to his wife in the next few days. I had the sense this was an unexpected question and that he sort of avoided answering... Giving his 'no answer' answer it was difficult for me to know if this was because she would be busy, or because she wouldn't be interested, or if he didn't want me to speak to his wife. Either way, I didn't speak to his wife. (Author's fieldnotes) 
Whilst the fieldnote extract above highlights some of the awkwardness in relying on men to introduce you to their wives or partners, this approach did however work in some situations. Another important aspect was that chain-referral sampling (Heckathorn 2002) proved much more difficult with women than with their fishing partners, as women did not share a network in the same way that male fishers did with each other. I simply did not manage to establish contacts with women outside the immediate family context using the technique of chain-referral. In other studies on women in fishing households (Britton 2012; Gerrard 1995), the presence of women's organisations avoided the challenges discussed here, but there was no such women's network present on the Llŷn peninsula. A further complication is that fishing, unlike farming, has a different spatial context in that the fishing home is not necessarily located in proximity to the place of work and the sea. As such, it is unlikely that the researcher studying fishing will simply encounter female partners without actively seeking to meet them.

A further challenge in getting women to participate in the research was that some expressed they had nothing to contribute to the discussion of fishing:

Interviewer: maybe we can talk a little bit about how fishing has been part of your life?

Partner: hmm... I don't know a lot about fishing. (FP-9)

As the interview extract with Female partner 9 reveals, her initial response to her life in a fishing family was that she did not have much knowledge about the subject. This might reflect what was also found by Williams (2008) and Gerrard (1995) — that women's knowledges have traditionally been excluded from fisheries issues and politics, and as such they are not used to expressing their views on the topic of fishing. This point is echoed by Power (2000, 202) who argues that women's lack of managerial and ownership control in fisheries 'may explain the uncertainty women express about their knowledge'. She continues: 
perhaps because of a history of government, industry and researchers deferring to the male authority in fishery-related areas, even when women are actually more knowledgeable about certain issues than their husbands and male relatives, and when they are asked to participate in discussions or comment publicly, they tend to defer to men.

Yet drawing on insights from studies of women in fishing families (Gustavsson and Riley 2018), we know that women have important knowledge and perspectives on fishing. As scholars often note, it is rare for women to work on fishing boats (with important local exceptions) instead, women are more commonly performing roles and activities that take place before or after capturing fish, such as preparing fishing gear, or selling, marketing and processing fish (see Frangoudes and Gerrard 2018; Weeratunge et al. 2010). However, whilst a lot of the discussion regarding fishing revolves around fishing practices, the following quote also highlights the importance of asking questions with relevance to women's lives — and the work they do_-in fishing families in the local context:

I don't know much about [fishing]. I wouldn't know how to catch crab and lobster. But I know a lot about fisheries. Do you know what I mean? I know a lot about that and as a family how to make a living out of fishing. I know quite a lot about that. (FP-17)

As a researcher, it is important to ask questions that are relevant to women, and which avoid debasing their knowledge of fishing practices. By this I mean that questions have to allow for women to 'tell their stories', going beyond discussing details of fishing practices and those activities placed at sea. Nevertheless, this is not to say that women do not have a stake or view in the politics, business or social practices. In a study of fishing families in Oregon, US, McGraw et al. (2000) noted that, whilst they experienced low response rates when seeking to engage women in fishing families, the women who did choose to participate were politically motivated to do so: 
We met considerable resistance from both potential and committed participants. We came to recognize that our goal of understanding family processes within a particular work and family context was not shared by some of our participants, who seemed to focus instead on changing policies to increase fishermen's "rights" to fish. (McGraw et al. 2000, 68-69)

This extract again highlights that seeking to understand women's fishing lives can sometimes be entangled in, and potentially overshadowed by, local and national politics and contentions around fishing policies. Getting access to the stories of women in fishing families (and beyond) is a complex undertaking, with women being embedded in a culture that often centres around that which takes place at sea, whilst often living lives in a terrestrial space performing activities that do not necessarily afford them much symbolic capital in the fishing 'field' (Gustavsson and Riley 2018). Thus, the argument I try to make here is that to access stories of women in fishing families, we have to be sensitive to the 'invisible', undervalued and supportive roles which women often perform in the industry (Zhao et al. 2013) — which shape how they narrate their own, their male partners' and their families' lives.

\subsection{Fishing Families and Group Interview Dynamics}

Several ethical and practical issues surround interviewing couples and family members together or as a group. An important advantage is that the presence of other family members can, in some situations, incidentally add important contributions to the narratives being produced (see Riley 2010). Nevertheless, many researchers have documented the benefits and challenges of doing interviews with, in particular, couples (see Valentine 1999). In her interviews with fishing households, Williams (2008, 64) writes:

My inquiries about housework sometimes caused bristling or sarcasm between couples. However, this is surely true of all interviews, and more often led to laughter. When interviewing couples together it was often dif- 
ficult to hear the woman's opinion on the fishing industry. Either the husband would immediately answer the question or the wife would defer to him. [...] Whereas in one-to-one interviews women usually offered confident, well-informed perspectives on these issues.

Similar issues to those that emerged in Williams' (2008) study certainly appeared in some of my interviews with fishing families. I found that, in couple interviews, women's stories and lived experiences sometimes became overshadowed by the more culturally central story of what it meant to be a 'fisher-man'. In couple interviews, women often tended to be 'co-narrators' in developing the narrative around the fishing industry and (men's) fishing practices_-resulting in them serving as a supporter of the arguably male narrative. I found that to access narratives about women's lived experiences, it was often important to have one-on-one interviews with them. Nevertheless, in some couple interviews the female partner contributed extensively to the interview discussion and, significantly, challenged some ways in which their fishing partner was narrating their lives:

Male fisher: '[fishing] is as hard as you want to make it...'

Female partner: '.... but you try to put rose colour spectacles.... But the reality of it is, hard, I don't know a harder job really. And then it is dangerous as well isn't it. Cause you have lost, how many colleagues have you lost in the last [years]?...' (MF-16 and FP-17)

Allowing partners to challenge the fisher's narrative provided a more nuanced understanding of the lifeworlds of fishing. The advantages of using couple interviews therefore were that it sometimes allowed for other perspectives on fishing to be reflected upon by both interview participants-perspectives which may have been missed if not interviewing the couple together. At the same time, not all male fishers welcomed having their stories challenged or the interceptions and additions by their female partners in the interview situation: 
In the couple interview there was a certain level of (one-directional) unkindness and hostility that emerged. I can't help to think that my questioning about the knowledge and perspective of the female partner might have provoked these mean comments from the male fisher. When discussing a particular fishing practice, the female partner, I thought, was humble and honest enough to highlight the limits of her knowledge around a particular practice. In response, her husband meanly commented: "you don't know much at all really. [Laughing]". I felt this was really mean and was intended to be hurtful. Hiding my dislike of what he had said I quickly moved away from this topic. (Author's fieldnotes)

As the fieldnotes extract above highlight, the interview also revealed unfriendly behaviours in couple interviews which could have potentially caused distress. When discussing the complex ethical choice of whether to interview couples together or separate, Valentine (1999) argues that no particular approach is better than the other but that particular ethical issues could emerge in both situations. Therefore, she argues, the researchers have to be reflexive and ethically probe social relationships and power dynamics present in the interview. The experience from my research, as revealed in the extracts above, reinforces Valentine's position as couples are different and the researcher has to be attentive to diverse and emergent (gendered) power relations. At the same time, whilst couple interviews had advantages in terms of allowing women and men to jointly shape narratives of the lives of fishing families, they were limited in the way that women's concerns and lived experiences sometimes became marginalised. To avoid some of these issues I, again, relied on repeat interviews. Riley and Harvey (2007) suggest that repeat interviews can reveal stories and information that were hidden within previous interviews because of the presence of another family member. Drawing on these insights I tried to return to some women in one-on-one settings to expand on some conversations that were difficult to be had within the couple interview context. This approach enabled me to gain an understanding of (gendered) couple dynamics and family life, as well as individual aspirations and lived experiences.

In addition to couple interviews, more recent research has begun to explore joint interviews between respondents with other types of familial 
relations. For example, Riley (2014) discusses the added value of interviewing fathers and sons together when discussing the topic of family farms. Riley $(2014,245)$ suggests 'the process of co-narration can add to the research encounter not only through the material that it may reveal, but also in terms of how such narratives are constructed, shared and (re) worked within the interview'. By drawing on this perspective I chose to explore, where possible, joint interviews with fathers and sons who either fished or did not fish together, as well as joint interviews with mothers and daughters. In reality, as argued earlier, it was not entirely possible to control who was present in the interview situation (neither in 'private' nor 'public' spaces) and therefore-whilst being aware of the (dis)advantages of, and being open to, joint interviews — most joint interviews were not planned but developed once in someone's home. The approach taken here was that I remained flexible and adapted to any changes that emerged 'in the field' - an approach which is largely echoing the rhythms, adaptability, flexibility and difficult-to-plan-ahead everyday life which fishers and fishing families are used to. I would argue that fisheries researchers should be prepared for these varying social dynamics and may benefit from embracing rather than resisting this 'messiness', to get a deeper sense of the workings of fishing families and cultures.

\subsection{Sensitive Topics and Ethical Interviewing}

Interviews with fishers and fishing families will often entail engaging with sensitive topics. Previous research has suggested that sensitive topics can unexpectedly arise particularly in unstructured, open-ended and narrative qualitative interviews, which may cause distress to participants (Corbin and Morse 2003). In the context of interviewing members of fishing families, the dangers associated with the fishing occupation can be especially sensitive. During my time in the field, I gradually realised that almost everyone I spoke to knew someone who had lost their life at sea. This observation has also been noted by Ross $(2015,8)$ who, by studying fishing communities in Scotland, argues that 'fishing communities' are held together as communities of grief. In her own words, these 'shared feelings of grief and loss inform peoples' sense of place, and also help 
people connect with one another across different coastal communities'. What this means in the context of people's everyday lives is explored in the following extract from one of my interviews:

Female partner: 'You know people are not used to having this type of family. They can't imagine how you must feel knowing that they are out there in bad weather. [...] I know it is very dangerous, I know it is one of the most dangerous jobs isn't it?! [...] Well two fishermen have died here. One a year ago and one 5 years ago... soo... that just brings it home, when something happens like that. [...] One of them was missing so they all went out for hours looking for him....'

Interviewer: '....I guess that must have been very hard for everyone'.

Female partner: 'yeah [crying]...'

Interviewer: 'I am sorry... I am asking sensitive questions'.

Female partner: 'No no no... I am fine, I am fine. I am fine, don't worry. It is fine. That is how I am anyway. I don't mind answering anything. It is just that I get emotional because it was [a family friend]. You ask me anything you want, don't worry about it. This is me. [My husband] would despair of me [laugh]'.

Interviewing: 'Good that he is not here then...'

Both: '[Laughing]' (FP-9)

Whilst the topic of loss and death is one obvious possible source of distress, the extract above reveals that other sensitive topics, such as the worries of those who remain onshore when their family members are out fishing in rough weather, have the potential to arouse powerful emotions. So too can fishers and family members' reflections on the dangers of their occupation or near-death experiences they have had in the past. Whilst I (possibly naively) did not anticipate this to happen, I would recommend researchers new to the field of fishing familiarise themselves with ethical interviewing principles and techniques (see Corbin and Morse 2003). Such literature suggests that whilst participants can become distressed, the 'risks are often contained and mitigated by the benefits that participants receive by telling their stories' (Corbin and Morse 2003, 341). In the above interview extract it is telling that the participant repeatedly stresses that she wants to continue the interview. 
Ethical interviewing sets out a number of guidelines and techniques for how to deal with distress and sensitive topics in an interview situation. If powerful emotions do occur, it is suggested that allowing participants time to compose themselves is a good idea. Corbin and Morse $(2003,343)$ go on to note that 'once a participant regains composure, he or she is usually given a choice about whether to continue with the topic, change to another topic, or terminate the interview'. Nevertheless, they suggest, it is advisable to follow cues from participants to judge if it may be necessary to abandon a topic if it is becoming too painful. The skill of the researcher is placed centrally to understanding how successfully these situations are dealt with. Corbin and Morse $(2003,343)$ argue that 'experienced researchers are able to step back and provide the empathy and support that participants might need to work through troubling experiences'. Given the frequent encounter with grief and loss in interviews with fishing families, it is therefore important for fisheries social scientists to be prepared to discuss and deal with sensitive topics beyond having formal ethics protocols in place.

\subsection{Positionality and Outsiderness}

Those taking a feminist approach have also highlighted the need to understand the role of the researcher and how research can be framed by relations between interviewer and interview participants (McDowell 1992). Whilst formal ethics procedures have been important to encourage less exploitative relations between participants and the researcher, other ethical issues, not often dealt with in formal ethics procedures (such as context-specific issues like grief mentioned above), are often present in the research (Dowling 2010). McDowell (1992, 409 original emphasis) argues: 'we [as researchers] must recognize and take account of our own position, as well as that of our research participants, and write this into our research practice rather than continue to hanker after some idealized equality between us'. Other researchers have suggested that, because of the central position of the researcher in producing the data, a process of 'critical reflexivity' needs to be undertaken (Dowling 2010; Kvale and Brinkmann 2011). 
One way in which researchers have tried to make visible the relations between themselves and participants is through the concept of positionality (Rose 1997; Tarrant 2013). In attempting to reflect on my own positionality, there were many aspects that would have led the respondents to consider me ('the researcher' or 'the student') an 'outsider'. In particular, my identity as female, foreign, probably middle-class, a young city person-and the 'intersectionality' (Tarrant 2013) of these-served to construct this outsiderness. In interviews, many fishers wanted to know about my background and frequently asked if I had any family history of fishing, as well as making inquiries about the sort of place I was from. The answer to these questions was always truthful - that is, there was no prior connections to fishing in the family nor was I from a fishing place. At one point, a fisher asked whether I had any experience of being on the sea and I answered that I had experience of sailing.

Interviewer: 'I have been quite a lot at sea. Sailing.'

Male fisher: 'Ah yeah, I have never been sailing in my life. Haha'. (MF-11)

Whilst the verbatim account of this interview extract only highlights that fishing and sailing are different experiences, I remember feeling that I had shared something which I thought would make me more of an insider. Instead, I remember feeling that my comment created more distance and resulted in reinforcing my status as an 'outsider' (cf. Kuehne 2016 for the case of farming):

Sometimes I think I couldn't be any more different from my research participants. This difference can really bother me, and it sometimes makes me anxious. The fishers I have spoken to this week have been asking questions about me. They probably want to be polite, but I can't stop myself from feeling judged. I sometimes wish I could say "I am from a fishing family" as that would somehow automatically make me part of it all. This would however be a lie, and I don't want to lie to my participants. (Author's fieldnotes)

As the extract above reveals, at the time of the fieldwork I had a strong sense that being perceived as an insider by the participants would somehow be a preferred position. However, after some distance and reflection 
I can identify particular advantages of being seen as an outsider. The first observation here relates to being perceived as 'unthreatening':

At one point a fisher asked me what I was going to do with all this information I was collecting. He then jokingly said "will you get your own boat and start fishing around here?”. This was obviously a joke. He genuinely couldn't conceive of me doing that. (Author's fieldnotes)

As revealed in the fieldnotes extract above, having an outsider status assisted in accessing detailed knowledge about fishing practices and fishers' business secrets. This observation is echoed by Chiswell and Wheeler (2016) who, in a study of farming practices, argue that their 'outsiderness' led respondents to explain practices of farming in detail as respondents did not assume them to have any prior knowledge about farming. The position of 'not knowing much about fishing' - embodied by myself in the research, also proved to be productive in terms of being able to ask fishers to give more details about their practices. In particular, by showing curiosity and interest, people were keen to explain and develop their narratives which probably would have been considered as 'taken for granted knowledge' within the fishing community. Associated with this, and reinforcing my outsiderness, was my identity as a young woman studying a largely male-dominated occupation. Echoing Horn's (1997) observations, it was sometime advantageous to be positioned as 'feminine' as this added to the appearance as unthreatening to the research participant. Similarly, Pini (2005) highlights the way participants understood her femininity as being a 'respectful listener', which in my research proved to be an advantageous position to adopt for enabling fishers to talk about their lives more broadly.

My outsiderness was further reinforced by my foreign status as a Swedish person living in the UK. The fishing community on the Llŷn peninsula-located in the so-called Welsh heartland (see Jones and Fowler 2007), with over $80 \%$ of the population being Welsh speakerswas primarily a Welsh-speaking fishing community:

99 percent of the fishermen here are all Welsh. [...] We are all Welsh speakers. We are all from the area. That is part of the community. [...] The terminology that [we fishers use] are all in Welsh. [...] I struggle to use English terminology because [...] you just learn to use Welsh terms for weather, for lobster gear, the boat, sea conditions. (MF-22) 
As a second-language English speaker, I felt I was kindly and generously accepted in the area by Welsh-speaking participants who were interviewed in English (often their second language as well). An evident challenge was that neither the researcher nor the research participant spoke their first language in the interview interaction, albeit both being proficient in the English language. This challenge, however, became an advantage as in the research encounter, both researcher and respondents had the patience to allow for pauses and struggles to find words in English, a process which with first-language speakers can become awkward and embarrassing. This experience thus became generally positive as my positionality allowed respondents to (sometimes) openly struggle with English-which contributed towards reducing some power imbalances. Nonetheless, there were some obvious disadvantages with interviewing participants in a language that they do not use to discuss fishing activities amongst each other. In particular, some of the nuances of expressions might have been lost in translation. The experience, however, was that fishers took the time to explain, translate and deconstruct the meaning of the expressions - which if spoken in the original language might have been taken for granted.

Taken together, the nervousness I initially felt about being an outsider was perhaps not necessary. Whilst I would argue it is important to be reflexive about your own position in the field and about potential issues around imbalanced power relations, being perceived as a curious outsider can work to the advantage of the researcher in getting access to participants, as well as the knowledge and narratives they develop in the interview.

As a final point, whilst my subject position as a 'woman' had some advantages in terms of collecting rich data, in some situations it forced me to compromise with some of my beliefs about, for example, the importance of gender equality. Although I was mostly open about my background and personality, some aspects of my identity were consciously disguised. In her study of Australian agriculture, Pini $(2004,174)$ found that her feminist identity brought 'significant negative connotations for participants' which would potentially hinder the possibility for 'sympathetic engagement with the context and culture' she wanted to research. Agreeing with this position, I chose to disguise my feminist identity and 
did not overtly challenge the masculinity embedded in the fishing community. This was particularly important as examining gender identities was one of the objectives of my research and these performances became informative of the ways in which fishers construct their masculinities (see Gustavsson and Riley 2020).

\subsection{Conclusion}

In this chapter, I have shared some of my own experiences 'in the field' with interviewing fishers and fishing families about their lifeworlds. The chapter examines some practical and ethical challenges specific to the fishing context, which have not been discussed in this way before. The empirical and methodological insights presented could be informative to other researchers wanting to engage with fishers and fishing families-in particular drawing on my lessons learned around getting access, performing interviews and reflections on interviewer-interviewee interactions. The chapter also offers insight into how to consider the gendering of fishing cultures when designing fieldwork and interview protocols. Whilst this study takes a qualitative approach, and as such offers guidance on how to apply qualitative approaches to the case of fishing, some aspects on how to approach fishers and their families, discussions on positionality, ethics and context-specific insights are applicable to other methodological approaches within studies of fishing. In particular, the chapter highlights the importance of considering the spatial context and the (gendered) social dynamics of interviews with fishers and fishing families and calls for more research on fisheries to consider-and be reflexive about - the choice of methodological approach and issues faced in the research encounter.

Acknowledgements I would like to thank the fishing families that volunteered their time to participate in the doctoral research project, funded by the School of Environmental Sciences, University of Liverpool, which informs this chapter. An ESRC New Investigator grant, under grant number ES/R00580X/1, supported time to write this chapter which served to develop the background for 
recruitment strategies in a research project on women in fishing families (www. women-fisheries.com). I also wish to thank Jeremy Phillipson, Kristen Ounanian, Mark Riley, Karyn Morrissey and Nathalie Ross for their comments on an earlier version of this chapter.

\section{References}

Aitken, Stuart. 2001. Shared Lives: Interviewing Couples, Playing with Their Children. In Qualitative Methodologies for Geographers: Issues and Debates, ed. Melanie Limb and Claire Dwyer, 73-85. London: Arnold.

Anbleyth-Evans, Jeremy. this volume. Exploring the Relationship Between Local Ecological Knowledge and Technology Through Participant Observation Onboard Fishing Vessels. In Researching People and the Sea: Methodologies and Traditions, ed. Madeleine Gustavsson, Carole S. White, Jeremy Phillipson, and Kristen Ounanian, 137-158. London: Palgrave.

Britton, Easkey. 2012. Women as Agents of Wellbeing in Northern Ireland's Fishing Households. Maritime Studies 11: 16. https://doi.org/10.1186/ 2212-9790-11-16.

Chiswell, Hannah M., and Rebecca Wheeler. 2016. 'As Long as You're Easy on the Eye': Reflecting on Issues of Positionality and Researcher Safety during Farmer Interviews. Area 48 (2): 229-235. https://doi.org/10.1111/ area. 12257.

Chiswell, Hannah, Julie Urquhart, Nick Lewis, Jasmine Black, Paul Courtney and Matt Reed. this volume. Safety, Ethics and Trust: Reflecting on Methodological Challenges in Fisheries Research. In Researching People and the Sea: Methodologies and Traditions, ed. Madeleine Gustavsson, Carole S. White, Jeremy Phillipson, and Kristen Ounanian, 91-112. London: Palgrave.

Corbin, Juliet, and Janice M. Morse. 2003. The Unstructured Interactive Interview: Issues of Reciprocity and Risks When Dealing With Sensitive Topics. Qualitative Inquiry 9 (3): 335-354. https://doi.org/10.1177/ 1077800403251757.

Crang, Mike, and Ian Cook. 1995. Doing Ethnographies. Norwich: Geobooks. Dowling, Robyn. 2010. Power, Subjectivity, and Ethics in Qualitative Research. In Qualitative Research Methods in Human Geography, ed. Iain Hay, 25-39. Toronto: Oxford University Press. 
Frangoudes, Katia, and Siri Gerrard. 2018. (En)Gendering Change in SmallScale Fisheries and Fishing Communities in a Globalized World. Maritime Studies 17: 117-124. https://doi.org/10.1007/s40152-018-0113-9.

Gerrard, Siri. 1995. When Women Take the Lead: Changing Conditions for

Women's Activities, Roles and Knowledge in North Norwegian Fishing Communities. Social Science Information 34 (4): 593-631. https://doi. org/10.1177/053901895034004004.

Gustavsson, Madeleine, and Mark Riley. 2018. Women, Capitals and Fishing Lives: Exploring Gendered Dynamics in the Llŷn Peninsula Small-Scale Fishery (Wales, UK). Maritime Studies 17: 223-231. https://doi.org/ 10.1007/s40152-018-0102-z.

. 2020. (R)evolving Masculinities in Times of Change amongst Small-

Scale Fishers in North Wales. Gender, Place \& Culture 27 (2): 196-217. https://doi.org/10.1080/0966369X.2019.1609914.

Gustavsson, Madeleine, Mark Riley, Karyn Morrissey, and Andy Plater. 2017. Exploring the Socio-Cultural Contexts of Fishers and Fishing: Developing the Concept of the 'Good Fisher. Journal of Rural Studies 50: 104-116. https://doi.org/10.1016/j.jrurstud.2016.12.012.

Heckathorn, Douglas D. 2002. Respondent-Driven Sampling II: Deriving Valid Population Estimates from Chain-Referral Samples of Hidden Populations. Social Problems 49 (1): 11-34. https://doi.org/10.1525/ sp.2002.49.1.11.

Horn, Rebecca. 1997. Not 'One of the Boys': Women Researching the Police. Journal of Gender Studies 6 (3): 297-308.

Jones, Rhys, and Carwyn Fowler. 2007. Where Is Wales? Narrating the Territories and Borders of the Welsh Linguistic Nation. Regional Studies 41 (1): 89-101. https://doi.org/10.1080/00343400600928343.

Kuehne, Geoff. 2016. Eight Issues to Think about before Interviewing Farmers. Forum: Qualitative Social Research 17 (2): 1-21.

Kvale, Steinar, and Svend Brinkmann. 2011. Den Kvalitativa Forskningsintervjun. 2nd ed. Lund: Studentlitteratur.

Mandel, Jennifer L. 2003. Negotiating Expectations in the Field: Gatekeepers, Research Fatigue and Cultural Biases. Singapore Journal of Tropical Geography 24 (2): 198-210. https://doi.org/10.1111/1467-9493.00152.

McDowell, Linda. 1992. Doing Gender: Feminism, Feminists and Research Methods in Human Geography. Transactions of the Institute of British Geographers 17 (4): 399-416. 
McGraw, Lori A., Anisa M. Zvonkovic, and Alexis J. Walker. 2000. Postmodern Families: A Feminist Studying Analysis of in Work Ethical Tensions and Family Research. Family Relations 62 (1): 68-77.

Palmer, Craig T. 1990. Balancing Competition and Cooperation: Verbal Etiquette among Maine Lobstermen. Maritime Studies 3 (1): 87-105.

Pálsson, Gísli. 1994. Enskilment at Sea. Man New Series 29 (4): 901-927. https://www.jstor.org/stable/3033974.

Pini, Barbara. 2004. On Being a Nice Country Girl and an Academic Feminist: Using Reflexivity in Rural Social Research. Journal of Rural Studies 20 (2): 169-179. https://doi.org/10.1016/j.jrurstud.2003.08.003.

2005. Interviewing Men: Gender and the Collection and Interpretation of Qualitative Data. Journal of Sociology 41 (2): 201-216. https://doi. org/10.1177/1440783305053238.

Power, Nicole G. 2000. Women Processing Workers as Knowledgeable Resource Users. In Finding Our Sea Legs: Linking Fishery People and Their Knowledge with Science and Management, ed. Barbara Neis and Lawrence Felt, 189-204. St. John Newfoundland: Institute of Social and Economic Research, Memorial University.

Riley, Mark. 2010. Emplacing the Research Encounter: Exploring Farm Life Histories. Qualitative Inquiry 16 (8): 651-662. https://doi.org/10.1177/ 1077800410374029.

- 2014. Interviewing Fathers and Sons Together: Exploring the Potential of Joint Interviews for Research on Family Farms. Journal of Rural Studies 36: 237-246. https://doi.org/10.1016/j.jrurstud.2014.09.003.

Riley, Mark, and David Harvey. 2007. Oral Histories, Farm Practice and Uncovering Meaning in the Countryside. Social \& Cultural Geography 8 (3): 391-415. https://doi.org/10.1080/14649360701488823.

Rose, G. 1997. Situating Knowledges: Positionality, Reflexivities and Other Tactics. Progress in Human Geography 21 (3): 305-320. https://doi. org/10.1191/030913297673302122.

Ross, Natalie. 2015. Understanding the Fishing 'Community': The Role of Communities of the Mind. Sociologia Ruralis 55 (3): 309-324. https://doi. org/10.1111/soru.12094.

Sampson, Helen, and Michelle Thomas. 2003. Lone Researchers at Sea: Gender, Risk and Responsibility. Qualitative Research 3 (2): 165-189.

Siriwardane-de Zoysa, Rapti, and Anna-Katharina Hornidge. 2016. Putting Lifeworlds at Sea: Studying Meaning-Making in Marine Research. Frontiers in Marine Science 3: 1-13. https://doi.org/10.3389/fmars.2016.00197. 
Tarrant, Anna. 2013. Negotiating Multiple Positionalities in the Interview Setting: Researching across Gender and Generational Boundaries. The Professional Geographer 66 (3): 493-500. https://doi.org/10.1080/0033012 4.2013.805621.

Urquhart, Julie, Tim Acott, Matt Reed, and Paul Courtney. 2011. Setting an Agenda for Social Science Research in Fisheries Policy in Northern Europe. Fisheries Research 108 (2-3): 240-247. https://doi.org/10.1016/j. fishres.2010.12.026.

Valentine, Gill. 1999. Doing Household Research: Interviewing Couples Together and Apart. Area 31 (1): 67-74. https://doi.org/10.1111/ j.1475-4762.1999.tb00172.x.

Weeratunge, Nireka, Katherine A. Snyder, and Choo Poh Sze. 2010. Gleaner, Fisher, Trader, Processor: Understanding Gendered Employment in Fisheries and Aquaculture. Fish and Fisheries. https://doi.org/10.1111/ j.1467-2979.2010.00368.x.

Williams, Ruth. 2008. Changing Constructions of Identity: Fisher Households and Industry Restructuring. Unpublished PhD thesis, Newcastle University. Zhao, Minghua, Marilyn Tyzack, Rodney Anderson, and Estera Onoakpovike. 2013. Women as Visible and Invisible Workers in Fisheries: A Case Study of Northern England. Marine Policy 37: 69-76. https://doi.org/10.1016/j. marpol.2012.04.013.

Open Access This chapter is licensed under the terms of the Creative Commons Attribution 4.0 International License (http://creativecommons.org/licenses/ by/4.0/), which permits use, sharing, adaptation, distribution and reproduction in any medium or format, as long as you give appropriate credit to the original author(s) and the source, provide a link to the Creative Commons licence and indicate if changes were made.

The images or other third party material in this chapter are included in the chapter's Creative Commons licence, unless indicated otherwise in a credit line to the material. If material is not included in the chapter's Creative Commons licence and your intended use is not permitted by statutory regulation or exceeds the permitted use, you will need to obtain permission directly from the copyright holder.

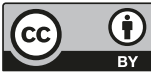

